\title{
Study of Adaptive Clothing in Hong Kong: Demands, Analysis and Future Direction
}

\author{
Jeffrey Yeung, Patrick C. L. Hui \\ Institute of Textiles and Clothing, The Hong Kong Polytechnic University, Hong Kong, China \\ Email: patrick.hui@polyu.edu.hk
}

How to cite this paper: Yeung, J. and Hui, P.C.L. (2020) Study of Adaptive Clothing in Hong Kong: Demands, Analysis and Future Direction. Advances in Aging Research, 9, 1-13.

https://doi.org/10.4236/aar.2020.91001

Received: October 29, 2019

Accepted: December 30, 2019

Published: January 2, 2020

Copyright $\odot 2020$ by author(s) and Scientific Research Publishing Inc. This work is licensed under the Creative Commons Attribution International License (CC BY 4.0).

http://creativecommons.org/licenses/by/4.0/

(c) (i) Open Access

\begin{abstract}
Aging population is substantively increased over last decade and they have specific clothing needs especially for the elderly with disabilities. Their clothing needs to cover functional and aesthetic requirements in order to improve their quality of life. Adaptive clothing is specially designed for the elderly and the disabled. However, there is no public policy to support such the elderly with disabilities in their clothing needs. In this paper, we aim to study the adaptive clothing and its significance, the problems encountered by the elderly with disabilities in adaptive clothing, analysis of public policy in Hong Kong for the elderly with disabilities in adaptive clothing over last decade, and implications and future directions for adaptive clothing in Hong Kong. In our findings, the demand of adaptive clothing in Hong Kong was substantially increased over last decade and the predicted demand will be twice of current demand after 50 years. However, the Government policy in Hong Kong has not yet fully supported their clothing needs, and the non-profit clothing services centre is set up to provide tailoring services to meet their needs. As the capacity of the centre is very limited, it is necessary to expand its capacity through assistive technology and to encourage non-government organizations (NGOs) to establish more social enterprises with Government's support. Such findings would be beneficial to the Government for strengthening such services for the elderly and the disabled as well as public awareness.
\end{abstract}

\section{Keywords}

Adaptive Clothing, Elderly with Disabilities, Public Policy

\section{Data Sources Used in This Study}

The primary search starts with the database of SAGE, Elsevier, Taylor \& Francis, Ovid, Google Scholar, Wiley online Library, Nature, Oxford Academics, ICI 
Journals master list, Scopus, Springer, Google and Yahoo. Relevant articles were systematically selected based on the key words and topics that have been published from the year 2000 until 2019. Key words of the primary search are listed as following sequence:

1) Adaptive Clothing.

2) Disabled/Elderly + garment.

3) Disabled/Elderly + apparel.

4) Disabled/Elderly + clothing.

5) Disabled/Elderly + government policy.

6) Disabled/Elderly + shopping.

\section{What Is Adaptive Clothing and Its Significance?}

Adaptive clothing consists of garments and footwear designed for the elderly and people with disabilities (PWD), and is designed to eliminate, or at least reduce, the impact of functional limitations of its wearer's body [1], enabling them to go about their everyday lives with nonrestrictive comfort. In addition, it also allows caregivers and nurses to more easily provide assistance to those in need.

That adaptive clothing increases the wearer's sense of autonomy and control over their body means that they can more meaningfully participate in their community [2], increasing their engagement in occupations, as well as prospects for education and employment-all of which have a great impact on their quality of life [3]. As a means of lowering the barriers to social participation that the elderly and PWD encounter, adaptive clothing enables them to be more socially involved; thus, it plays a role in reducing the negative consequences of physical and mental problems, such as higher rates of coronary heart disease, stroke, depression, and cognitive decline [4], that arise from social isolation.

Clothing is fundamental to identity and self-image; it influences how one thinks, feels, and is perceived [5]. Therefore, aesthetic considerations figure just as much as functional considerations when it comes to adaptive clothing. In a society that privileges the needs and interests of the able-bodied, it comes as no surprise that the clothing choices of people with physical impairments are based on a desire to meet the dominant socio-cultural standards of appearance, so as to increase social acceptance and minimize differences from non-disabled peers [6] [7]. As such, fashionable adaptive clothing that fulfills its wearers' pursuit for style and image can positively influence wearers' self-concept, self-esteem, and body image, which in turn bolster cognitive functioning, mental health, and physical health [6].

\section{Demands of Adaptive Clothing in Hong Kong from the Elderly and PWD}

The need and demand for adaptive clothing will undoubtedly increase in the future. After all, Hong Kong is in the midst of a demographic shift. According to the most recent survey that the Census and Statistics Department has conducted 
in 2013, there are 320,500 people with restricted body movement. Aging in the population has increased the number of people with restricted body movement [8]. As the findings from the report show, $78.4 \%$ of people with restricted body movement are above 65 years old. This already-high proportion will increase in the coming years, as people aged 65 and above are estimated, according to Population Projections 2017-2066, to account for 27\% of the population, which is almost twice as that in 2016 (16\%) [9]. Given the projected increase in people aged 65, which also entails an increase in people with restricted body movement, the significance and need for accessible adaptive clothing ought to be considered just as much as other much-welcomed initiatives to improve the well-being of PWD and the elderly.

\section{Current Government Policy for Supporting the Elderly and PWD in Hong Kong}

Over the years, the Hong Kong government has demonstrated an awareness of the ways in which disabilities are very much social problems created and intensified by environmental barriers in society. In terms of policy, it has addressed the need to lower these environmental barriers, through measures such as the expansion of barrier-free and assistive transport and facilities [10]. And when it comes to policy that addresses disability as an individual, medical matter, there have been programs in place to reduce the impact of PWD's functional limitations of their body. Beyond disability allowances under the Social Security Allowance (SSA) and Comprehensive Social Security Assistance (CSSA) schemes, the Support Programme for Employees with Disabilities subsidizes employers to procure assistive technological devices and modify workplace environments to facilitate employees with disabilities, and the Innovation and Technology Fund for Application in Elderly and Rehabilitation Care subsidizes elderly and rehabilitation service units to procure products to improve PWD and the elderly's quality of life [11] [12]. The Rehabilitation Advisory Committee (RAC) that is tasked by the government to formulate a Rehabilitation Programme Plan has also proposed a Funding Scheme on Life-supporting and Assistive Devices, in order to provide financial support for persons with disabilities/rare diseases in purchase of the equipment and encourage them for employment [13].

\section{Problems Encountered by the Elderly and PWD in Adaptive Clothing}

Curiously, while there are measures to make the built environment more barrier-free, as well as to provide assistive technology to improve the elderly and PWD's ability to navigate the built environment, there is no consideration that adaptive clothing is just as helpful as assistive devices in diminishing disablement. A search through government websites, as well as the policy addresses from the past five years, yields no results regarding policy that explicitly aims to meet the elderly and PWD's need for adaptive clothing, suggesting that the rela- 
tionship between the marginalization of people with disabilities and access to adaptive clothing remains unacknowledged in policy-making circles. Besides this, it is difficult for the elderly and PWD to buy their required adaptive clothing in the commercial market because their adaptive clothing is very difficult for standardization in mass production to reduce the production cost. Thus, commercial apparel retailers are reluctant to set up a product line of such adaptive clothing for the elderly and PWD.

\section{How to Resolve the Problem for Adaptive Clothing in Hong Kong?}

In Hong Kong, there are some non-government organizations (NGOs) to provide a tailoring service for the elderly and PWD in a case-by-case basis. Such tailoring services are provided by rehabilitation therapists because they know their clothing needs based on their degree of disabilities. However, rehabilitation therapists do not have full knowledge of clothing making with fabric materials. Thus, the textile and clothing professional services provided by the University are catering for such tailoring services for the elderly and PWD with support of rehabilitation therapists.

\section{Setup of Non-Profit Servicing Centre and Social Enterprise for Adaptive Clothing}

In the absence of policies to expand the provision of and access to adaptive clothing, only Hong Kong Polytechnic University's Troels H. Povlsen Care Apparel Center (CAC) and Home Care Apparel respectively, a small-scale non-profit and a social enterprise, set up to provide adaptive clothing for the elderly and PWD. The small-sized nature of these centers ensues that the provision of and access to adaptive clothing remains inadequate for the elderly and PWD population, and this undoubtedly contributes to the disablement process the population faces, in spite of a wide-ranging series of policies to address their needs.

The significance of adaptive clothing for the elderly and PWD should not be understated. It is just like assistive devices, such as wheelchairs and catheter bags, in that it fulfills the elderly and PWD's utilitarian need to better meet the demands of everyday life. Additionally, adaptive clothing fulfills the elderly and PWD's hedonic need for self-expression [7], should it be designed to be aesthetically pleasing, which is something that assistive devices cannot fulfill. Accordingly, any attempt by the government and the RAC to formulate a comprehensive plan for the rehabilitation and habilitation of the elderly and PWD needs to take into account the role of adaptive clothing in diminishing disablement and improving mental and physical well-being.

\section{Facts Findings of Adaptive Clothing in Hong Kong over Last Decade}

This section examines the data that the CAC has collected from 2007 to 2017 
with regards to the adaptive clothing it has sold to its customers (see Table 1).

Figure 1 illustrates the number of adaptive clothing items purchased from

Table 1. The number of institutional and individual purchases at CAC from 2007-2017.

\begin{tabular}{cccc}
\hline Year & Individual purchases & Institutional purchases & $\begin{array}{c}\text { Total items cumulatively } \\
\text { purchased by year }\end{array}$ \\
\hline 2007 & 331 & 0 & 331 \\
2008 & 700 & 0 & 1031 \\
2009 & 503 & 0 & 1534 \\
2010 & 615 & 71 & 2220 \\
2011 & 735 & 62 & 3017 \\
2012 & 1019 & 125 & 4161 \\
2013 & 841 & 95 & 5097 \\
2014 & 1058 & 2010 & 8165 \\
2015 & 1273 & 435 & 9873 \\
2016 & 1108 & 189 & 11,170 \\
2017 & 1003 & 198 & 12,371 \\
Total items purchased & 9186 & 3185 & 12,371 \\
\hline
\end{tabular}

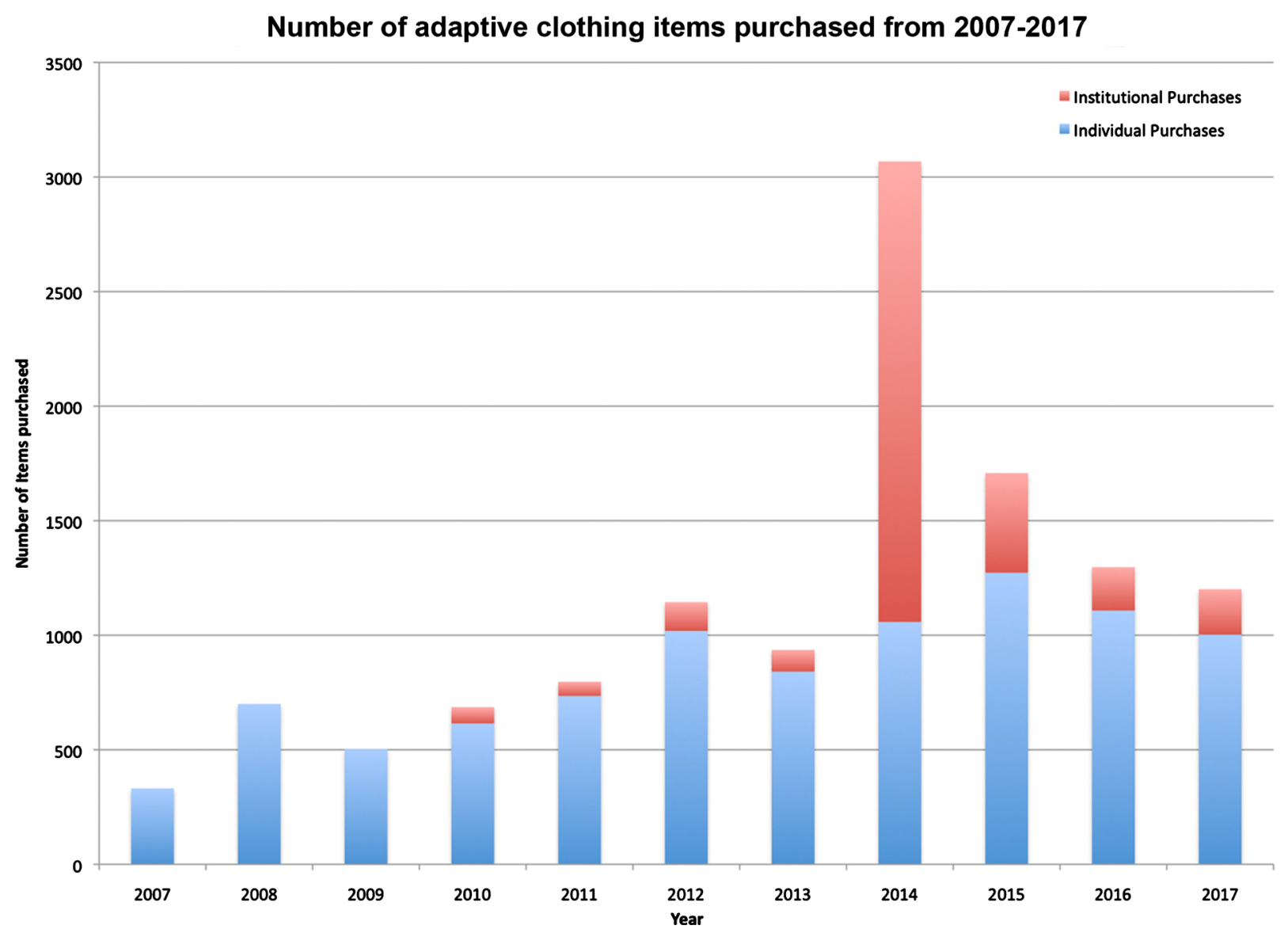

Figure 1. Number of adaptive clothing items purchased from 2007 to 2017 in Care Apparel Centre (CAC). 
2007 to 2017. Purchases are split into two categories: institutional and individual, with the former consisting of purchases made by private and public institutions ranging from public hospitals to elderly centers run by NGOs (see Table 2 ), and the latter consisting of purchases made by individuals.

It can be seen that the individual purchases increase in a roughly linear manner from 2007 to 2013. From 2014 to 2017, the purchases stop increasing. They peak and hover around an average of 1111 purchases a year. Meanwhile, the institutional purchases do not increase and peak in the same way that individual purchases do. Setting aside the unusually high number of institutional purchases of 2010 and 435 items in 2014 and 2015 respectively, the average number of items purchased by institutions is 82 .

There is no pattern to the institutional purchases throughout the decade, because these purchases are contingent upon whether institutions decide to purchase adaptive clothing items through Care Apparel Center. The purchase records show that all of the items that are usually purchased in bulk by these institutions are mass-produced ones that CAC sources from adaptive clothing suppliers. As such, institutions do not necessarily have to make their purchases through CAC, because there exist many suppliers in Hong Kong that offer mass-produced adaptive clothing items, such as non-slip socks and disability aid aprons, the top two most ordered items (see Table 3). This explains why no trend can be discerned from the bulk purchases throughout the decade.

On the other hand, individual purchases have increased from 2007-2013, and then peaked from 2014-2017 at an average of 1111 items purchased a year. While the increase in individual purchases from 2007-2013 can simply be attributed to an increased awareness among elderly and disabled consumers with regards to CAC, the fact that purchases have stayed more or less constant from 2014-2017 is a consequence of CAC's limited ability in meeting the demand of its customers.

The nature of the most purchased items from individual purchases generally differs from the items purchased by various institutions (see Table 3 ). All of the adaptive clothing items that CAC sells to various institutions are mass-produced items that the center sources from various suppliers. Some of the items that individuals purchase are also mass-produced, such as non-slip socks, constraint mittens, and disability aid aprons. Many more are custom-made adaptive clothing items that are modified, tailored and manufactured to fit the specifications that individual customers require. For instance, the most ordered item from non-bulk purchases is a protective shirt, and customers who order a protective shirt from CAC experience a variety of physical impairments, many of which a pre-made protective shirt cannot address. A customer may require a special pocket to conceal the urine bag they carry with them, an attached arm sling on which to rest their arm, an enlarged zipper tab for those with finger dexterity impairments, and so on. CAC's two full-time tailors would have to take the measurements of these customers in order to manufacture a customized protective shirt for them. It also has to be noted that Table 3 only shows the most ordered 
Table 2. Institutional purchases from 2007 to 2017.

\begin{tabular}{|c|c|c|c|c|}
\hline Item name & Year purchased & Institution that made the purchase & Quantity & Total \\
\hline \multirow[t]{16}{*}{ Non-slip socks } & 2010 & Jockey Club Cadenza Hub & 24 & 2406 \\
\hline & & Lei Tung Neighbourhood Elderly Centre & 16 & \\
\hline & 2011 & Rhythm Garden Lutheran Centre for the Elderly & 18 & \\
\hline & & Hong Kong Phab Association & 9 & \\
\hline & 2012 & Jockey Club Cadenza Hub & 10 & \\
\hline & 2013 & Tung Wah Group of Hospitals & 60 & \\
\hline & & HKSKH Li Ka Shing Care and Attention Home for the Elderly & 58 & \\
\hline & & Jockey Club Cadenza Hub & 20 & \\
\hline & 2014 & Po Leung Kuk & 1500 & \\
\hline & & Po Leung Kuk Lau Chan Siu Po District Elderly Community Centre & 200 & \\
\hline & & Po Leung Kuk Lau Chan Siu Po Neighbourhood Elderly Centre & 150 & \\
\hline & & Li Ka Shing Care and Attention Home for the Elderly & 100 & \\
\hline & & Po Leung Kuk Li Shiu Chung Memorial Rehabilitation Centre & 10 & \\
\hline & 2015 & HK Spinocerebellar Ataxia Association & 182 & \\
\hline & & North District Hospital-Physiotherapy Service & 44 & \\
\hline & 2017 & Christian Family Service Centre Yang Chen House & 5 & \\
\hline \multirow[t]{9}{*}{ Disability aid apron } & 2010 & Lei Tung Neighbourhood Elderly Centre & 1 & 222 \\
\hline & 2011 & Yee on Care and Attention Home & 35 & \\
\hline & 2012 & HK Young Women's Christian Association & 100 & \\
\hline & & Yan Chai Hospital & 5 & \\
\hline & 2014 & Tung Wah Group of Hospitals Chan Han Home for the Elderly & 20 & \\
\hline & 2015 & HK Christian Service Shun Lee Home for the Elderly & 20 & \\
\hline & 2016 & $\begin{array}{c}\text { Tung Wah Group of Hospitals_Chiang Wai Fong Care \& } \\
\text { Attention Home }\end{array}$ & 20 & \\
\hline & & HK Society for the Blind & 18 & \\
\hline & & Lok Sin Tong Chan Lai Jeong Kiu Neighbourhood Elderly Centre & 3 & \\
\hline \multirow[t]{9}{*}{ Constraint gloves } & 2010 & HKSKH Cyril and Amy Cheung Aged Care Complex & 30 & 105 \\
\hline & 2013 & Tung Wah Group of Hospitals & 10 & \\
\hline & 2014 & Cheshire Home & 29 & \\
\hline & 2015 & Fu Hong Society Oi Wah Home & 5 & \\
\hline & & Kwun Tong Kwong Yum Home for the Aged & 2 & \\
\hline & 2016 & Fu Hong Society & 20 & \\
\hline & & Wai Ji Christian Service & 1 & \\
\hline & 2017 & Macau: Lar Ciudados "Sol Nascente" da Areia Preta & 7 & \\
\hline & & Cheshire Home & 1 & \\
\hline Wheelchair rain jacket & 2015 & St. James' Settlement Evergreen Day Care Centre for the Elderly & 5 & 86 \\
\hline
\end{tabular}




\section{Continued}

Disability apron (Chinese style)

\section{Constraint mittens}

Secure-fix sleep belt

Anti-strip pants

Non-slip vest

Constraint wrist strap

Outfit: vest, undershirt and shirt

Non-slip belt

Finger contracture cushion

$$
\text { Hand strap }
$$

Constraint vest

Wheelchair arm rest cover

Wheelchair back cushion

Wheelchair protective cover

Wrist band

Urine bag
2016

2016

2015

2015

2016

2017

2015

2016

2017

2016

2017

2015

2015

2017

2015

2012

2016

2017

2017

2016

2017

2016

2017

2016

2016
Kit Hong Home

Yee on Care and Attention Home

Ebenezer New Hope School

Sze Tian Rhenish Home for the Elderly

Wong Chuk Hang Service for the Elderly

Hong Kong Young Women's Christian Association

St. James' Settlement

HK Society for the Blind

Tung Wah Group of Hospitals-Chiang Wai Fong Care \& Attention Home

Zhongshan Yangfan Social Work Service Center

澳門菩提長者綜合服務中心

澳門菩提長者綜合服務中心

Macau: Lar de Cuidados "Sol Nascente" da Areia Preta

Macau: Lar Ciudados "Sol Nascente" da Areia Preta

\section{澳門黑沙環護老療養院}

HKSKH St. Paul's Home for the Elderly

Macau: Lar Ciudados "Sol Nascente" da Areia Preta

Wong Chuk Hang Service for the Elderly

Christian Family Service Centre Yang Chen House

Macau: Lar de Cuidados "Sol Nascente” da Areia Preta

Macau: Lar Ciudados “Sol Nascente” da Areia Preta 18

\section{澳門菩提長者綜合服務中心}

澳門菩提長者綜合服務中心

New Territories East Cluster Procurement Centre

Kwun Tong Kwong Yum Home for the Aged

Kowloon Hospital

Neighbourhood Advice-Action Council

New Territories East Cluster Procurement Centre

Cheshire Home

HK Christian Service Pui Oi School

Neighbourhood Advice-Action Council

HK Paralympic Committee \& Sports Association for the Physically

$$
\text { Disabled }
$$

St. James' Settlement

Po Leung Kuk Li Shiu Chung Memorial Rehabilitation Centre

Lei Tung Lutheran Day Activity Centre \& Hostel

Zhongshan Yangfan Social Work Service Center
61

36 


\section{Continued}

\begin{tabular}{ccccc}
\hline Waist strap & 2016 & Po Leung Kuk Li Shiu Chung Memorial Rehabilitation Centre & 2 & 2 \\
Knee strap & 2016 & Po Leung Kuk Li Shiu Chung Memorial Rehabilitation Centre & 2 & 2 \\
Wheelchair rain cover & 2017 & St. James' Settlement & 2 & 2 \\
Zipper & 2017 & Caritas Fu Heng Home & 1 & 1 \\
Protective shirt & 2014 & Cheshire Home & 1 & 1 \\
Fingerless gloves & 2017 & Salvation Army Po Lam Residence for Senior Citizens & 1 \\
Female top & 2016 & Zhongshan Yangfan Social Work Service Center & 1 & 1 \\
Undershirt & 2016 & Zhongshan Yangfan Social Work Service Center & 1 & 1 \\
Umbrella sling and waist bag & 2016 & Sze Tian Rhenish Home for the Elderly & 1 \\
Neck pillow & 2016 & Li Chan Yuk Sim Elderly Home & 1 \\
\hline
\end{tabular}

Table 3. Most purchased items made by institutions and individuals from 2007-2017.

\begin{tabular}{cccc}
\hline $\begin{array}{c}\text { Most purchased items by institutions } \\
\text { (which CAC has sourced from various } \\
\text { suppliers) }\end{array}$ & $\begin{array}{c}\text { Number of items } \\
\text { purchased }\end{array}$ & $\begin{array}{c}\text { Most purchased items } \\
\text { by individuals }\end{array}$ & $\begin{array}{c}\text { Number of items } \\
\text { purchased }\end{array}$ \\
\hline Non-slip socks & 2406 & Protective shirt & 1659 \\
Disability aid apron & 222 & Disability aid apron & 574 \\
Constraint gloves & 105 & Constraint mittens & 482 \\
Wheelchair rain jacket & 86 & Non-slip socks & 439 \\
Disability aid apron (Chinese style) & 61 & Wheelchair rain jacket & 365 \\
Constraint mittens & 60 & U-pants & 191 \\
Secure-fix sleep belt & 47 & Drop front pants & 165 \\
Anti-strip jumpsuit & 46 & Safety shoes & 141 \\
Anti-strip pants & 36 & Protective pants & 123 \\
Non-slip vest & 30 & Pajamas & 89 \\
\hline
\end{tabular}

*Many of these most ordered items are either variously sourced from suppliers, upon which modifications are made on many occasions, or manufactured from scratch to meet the specifications that customers request.

items from individual purchases, leaving out a record of the remaining 4958 individual purchases. Many of less commonly purchased items also require the CAC's tailors to manufacture or modify. Due to CAC's small size and high workload, customers usually have to wait several months to pick up the customized adaptive clothing they have ordered.

Lastly, Table 4 shows the number of individual customers who have made purchases from CAC throughout the decade. As expected, the number of customer increases over the years and peaks in the same way that the individual purchases depicted in graph 1 do, averaging at 397 customers between 2014 and 2017. A considerable number of CSSA recipients have purchased adaptive clothing from CAC throughout the decade, comprising an average of $31 \%$ of the customer base. That said, the percentage of customers who are CSSA recipients 
Table 4. The number of individual customers, and the CSSA recipients among the individual customers, who purchased adaptive clothing items from 2007 to 2017.

\begin{tabular}{cccc}
\hline Year & $\begin{array}{c}\text { Number of individual } \\
\text { customers }\end{array}$ & $\begin{array}{c}\text { Number of CSSA recipients } \\
\text { among individual customers }\end{array}$ & $\begin{array}{c}\text { Percentage of CSSA } \\
\text { recipients (\%) }\end{array}$ \\
\hline 2007 & 202 & 75 & 37 \\
2008 & 257 & 80 & 31 \\
2009 & 209 & 92 & 44 \\
2010 & 290 & 124 & 43 \\
2011 & 297 & 128 & 43 \\
2012 & 275 & 75 & 27 \\
2013 & 300 & 43 & 14 \\
2014 & 384 & 80 & 21 \\
2015 & 413 & 102 & 25 \\
2016 & 394 & 124 & 31 \\
2017 & 398 & 98 & 25 \\
\hline
\end{tabular}

is certainly higher than the data lets on. Representatives from institutions such as an elderly center or a hospital regularly purchase adaptive clothing items on behalf of the people they care for, perhaps making use of the subsidies obtained from the Innovation and Technology Fund for Application in Elderly and Rehabilitation Care. This results in purchases that are not registered as a purchase made by a CSSA recipient. In any case, the considerably high proportion of purchases made by CSSA recipients is indicative of the fact that a large number of PWD require social welfare allowances and services. Indeed, the government's 2013 poverty situation report reveals that around 80\% of PWD are eligible for social security benefits, and that only $39.1 \%$ of the 180,000 PWD of working age are economically active [14] [15].

\section{Implications and Further Actions for Adaptive Clothing in Hong Kong}

Data from the CAC's records show that there is a high demand among the PWD and elderly for both mass-produced and customized adaptive clothing. The CAC does its best to meet this demand, but due to its small size, its ability to procure, manufacture, modify, and repair adaptive clothing items is limited. As a result, customers have to wait for several months to fulfill their requests for adaptive clothing, especially customized ones, due to the heavy workload of the tailors in the CAC.

In anticipation of Hong Kong's aging population, which correlates with an increase in PWD, measures have to be taken to expand access to and provision of adaptive clothing, especially for a PWD population that is disproportionately unemployed, underemployed, and requiring of welfare services. CAC's purchase records show that apparel products designed and marketed towards the mass 
market cannot meet all the needs of the PWD and elderly population, due to the range of physical variations of consumers with physical impairments, which necessitate large quantities of customized adaptive clothing.

For this reason, the establishment of a government-funded, public rehabilitation equipment center may be one of the most appropriate ways to fulfill the growing demand for customized adaptive clothing, as the RAC's Rehabilitation Programme Plan recommends [16]. Such an equipment center can feature a much larger center than the existing CAC. It could train and hire PWD for tailoring services, and it could offer its PWD and elderly clients customized adaptive clothing at a subsidized price, or even for free, to honor the notion that PWD is entitled to habilitation services as a basic human right.

In contrast, establishing more social enterprises that provide tailoring services for customers who want to buy customized adaptive clothing is less preferable, because of their need to earn a profit in order to be sustainable. The Fullness of Social Enterprises Society Report published in 2015 paints a bleak picture of the social enterprises' ability to sustain themselves-23\% of SEs closed within 5 years, and the non-survival rate increased 55\% within 10 years [17]. Given the low socio-economic background that PWD disproportionately belongs to, it does not seem appropriate for PWD customers to purchase customized clothing at a social enterprise. After all, the lack of competitive markets for adaptive clothing entails that the tailoring services offered for PWD customers, as well as the production of customized adaptive clothing, will be quite costly. Moreover, social enterprises need to maximize their profits in order to maintain and expand their operations-to profit off a marginalized group's need for adaptive clothing is not ideal. That said, elderly and PWD customers may not have to worry about the potentially high costs of customized adaptive clothing, given that many are fully subsidized by the government initiatives that grant them disability allowances and vouchers for these purchases. Even so, the fundamental problem remains: social enterprises like Home Care Apparel and non-profits like Care Apparel Center are too small to fulfill the burgeoning demand for customized adaptive clothing.

Lastly, to craft policies that are responsive to existing and rising demand for adaptive clothing, it may do well for the RAC and the Hong Kong Government to expand their conception of assistive technology and devices, so as to bring adaptive clothing within its fold. Browsing the information pages of programmes such as the Innovation and Technology Fund for Application in Elderly and Rehabilitation Care [18], as well as RPP's proposals of a Funding Scheme on Life-supporting and Assistive Devices, and Community Care Service Voucher for the Elderly [19], one gets the impression that assistive technology is mainly conceived as electronic devices and equipment such as wheelchairs and urine drainage bags. If assistive technology was defined as devices and equipment that maintain, increase, or improve the abilities of individuals with disabilities [1], then adaptive clothing belongs to this category, and should be perceived 
to be just as integral as the likes of wheelchairs, hearing aids, and prosthetic devices in diminishing PWD's disablement and improving their well-being. Accepting an expanded conception of assistive technology would make it likelier for policy-making bodies to consider the significance of adaptive clothing, and entertain the possibility of establishing a large, public Care Apparel servicing center that would expand tailoring services for customized adaptive clothing.

\section{Conflicts of Interest}

The authors declare no conflicts of interest regarding the publication of this paper.

\section{References}

[1] Disabled World (2019) Disability Adaptive Clothing for Disabled and Elderly. https://www.disabled-world.com/assistivedevices/adaptive-clothing.php

[2] De Leon, M., Glass, T.A. and Berkman, L.F. (2003) Social Engagement and Disability in a Community Population of Older Adults: The New Haven EPESE. American Journal of Epidemiology, 157, 633-642. https://doi.org/10.1093/aje/kwg028

[3] Kabel, A. (2016) Apparel-Related Participation Barriers: Ability, Adaptation and Engagement. Disability and Rehabilitation, 38, 2184-2192.

https://doi.org/10.3109/09638288.2015.1123309

[4] Wong, A., Chau, A.K.C., Fang, Y. and Woo, J. (2017) Illuminating the Psychological Experience of Elderly Loneliness from a Societal Perspective: A Qualitative Study of Alienation between Older People and Society. International Journal of Environmental Research and Public Health, 14, 824. https://doi.org/10.3390/ijerph14070824

[5] Chan, A., Peabody, G., Simpson, C. and de Souza, S. (2018) Garment+: Challenging the Boundaries of Fashion for Those with Long-Term Physical Disabilities. The Journal of Dress History, 2, 27.

[6] Kabel, A., McBee-Black, K. and Dimka, J. (2018) Apparel-Related Participation Barriers: Ability, Adaptation and Engagement. Disability and Rehabilitation, 38, 2184-2192.

[7] Xu, Y.J. and Annett-Hitchcock, K. (2015) Shopping and Virtual Communities for Consumers with Physical Disabilities. International Journal of Consumer Studies, 39, 136-144. https://doi.org/10.1111/ijcs.12161

[8] Census and Statistics Department, The Government of HKSAR (2014) Special Topics Report No. 62, Persons with Disabilities and Chronic Diseases. https://www.statistics.gov.hk/pub/B11301622014XXXXB0100.pdf

[9] Hong Kong Rehabilitation Programme Plan Team (2018) Scoping Stage Public Engagement Exercise: Information Pack for Participants.

http://www6.rs.polyu.edu.hk/rpp/wp-content/uploads/sites/8/2018/03/InformationPack-for-Participants.pdf

[10] Office of the Chief Executive, the Government of HKSAR (2016) The 2016 Policy Address, Tamar, Hong Kong; Office of the Chief Executive, the Government of HKSAR (2017) The 2017 Policy Address, Tamar, Hong Kong.

[11] Social Welfare Department, the Government of HKSAR (2019) Hong Kong: The Facts-Social Welfare. https://www.swd.gov.hk/en/index/site_pubpress/page_fact 
[12] Social Welfare Department, the Government of HKSAR (2019) Social Security Allowance (SSA) Scheme.

https://www.swd.gov.hk/en/index/site_pubsvc/page_socsecu/sub_ssallowance

[13] Hong Kong Rehabilitation Programme Plan Team (2018) Report on Scoping Stage. https://www.6.rs.polyu.edu.hk/rpp/wp-content/uploads/sites/8/2018/12/Report_on Scoping_Stage_eng.pdf

[14] Commission on Poverty, the Government of HKSAR (2014) Hong Kong Poverty Situation Report on Disability 2013.

https://www.povertyrelief.gov.hk/eng/pdf/Hong_Kong_Poverty_Situation_Report_ on_Disability_2013(E).pdf

[15] Chan, A.C.M. (2019) People with Disabilities in Hong Kong Need Jobs, Not Just Handouts. South China Morning Post.

https://www.scmp.com/comment/insight-opinion/article/2065247/people-disabiliti es-hong-kong-need-jobs-not-just-handouts

[16] Hong Kong Rehabilitation Programme Plan Team (2019) Report on Scoping Stage. 21.

[17] Leung, S., Mo, P., Ling, H., Chandra, Y. and Sum Ho, S. (2019) Enhancing the Competitiveness and Sustainability of Social Enterprises in Hong Kong: A Three-Dimensional Analysis. China Journal of Accounting Research, 12, 157-176. https://doi.org/10.1016/j.cjar.2019.03.002

[18] Social Welfare Department, the Government of HKSAR (2019) I \& T Fund: Reference List of Recognized Technology Application Products.

https://www.swd.gov.hk/storage/asset/section/3229/en/Reference_List-08.2019.pdf

[19] Social Welfare Department, the Government of HKSAR (2019) List of Recognized Service Providers under the Pilot Scheme on Community Care Service Voucher for the Elderly (Second Phase).

https://www.swd.gov.hk/storage/asset/section/2733/en/Full\%20List/5.8.2019/RSP_F ull_List_as_at_5.8.2019_Revised_ENG.pdf 